\title{
Knowledge, Attitude And Practice Of Infant And Young Child Feeding Among Mothers With Children (0-24 Months) In Umuahia South L.G.A.
}

\author{
M. O Kalu' ${ }^{1} \&$ S.N.O. Ibe ${ }^{2}$ \\ Department of Public Health, School of Health Technology, Federal University of Technology, Owerri, Imo State, Nigeria. \\ DOI: 10.29322/IJSRP.11.12.2021.p12010 \\ http://dx.doi.org/10.29322/IJSRP.11.12.2021.p12010
}

\begin{abstract}
Malnutrition is the commonest cause of death of children under 2 years of age. The study determined the knowledge, attitude and practice of infant and young child feeding among mothers with child 0-24 months in Umuahia South Local Government Area of Abia State. Descriptive survey research design was used for the study and the target population was 5325 nursing mothers attending post-natal clinics in the study area. The sample size was 327 and the respondents were drawn from the target population using simple random sampling technique. Instrument for data collection was a structured questionnaire and Statistical Package for Social Science (SPSS) was employed for data analysis. Results showed that majority of the respondents $(332,89.2 \%)$ have heard of exclusive breastfeeding, 330 (88.7\%) knew of the meaning of exclusive breastfeeding, 229 (77.7\%) knew when to commence complimentary feeding and 167 (44.9\%) stated correctly the right consistency of the food of child aged 6-9 months. More respondents 239 (64.2\%) strongly agreed that the baby should be exclusively breastfeed for the first six months of life, 199 (53.9\%) strongly agreed that colostrum should not be discarded and $310(83.3 \%)$ strongly agreed that there is no difficulty in breastfeeding infants exclusively. Dimensions of exclusive breastfeeding practiced included putting baby skin to skin after delivery $(220,59.1 \%)$, giving breast milk as first food $(231,62.1 \%)$ and rooming-in $(272,73.1 \%)$. More $(180,48.4 \%)$ fed their infants 4 or more times a day from age 6 months. It was surprising that despite several years of efforts by government and non-governmental agencies at all levels; international, national and local, many mothers were yet to adopt the global strategy for infant and young child feeding. The study concluded that previous efforts are yet to achieve the desired effects in this LGA. There is need for participatory evaluation of ongoing programmes and restrategizing implementation for effectiveness.
\end{abstract}

Index Terms- Knowledge, Attitude, Practice, Infant, Young-child, Feeding

\section{INTRODUCTION}

$\mathrm{A}$ dequate nutrition is fundamental to the development of any child to be able to achieve its full potential. Consequences of poor nutrition is early childhood include significant illnesses, delayed mental and physical development and death NPHCDA

This publication is licensed under Creative Commons Attribution CC BY.

http://dx.doi.org/10.29322/IJSRP.11.12.2021.p12010
(2012). Breastfeeding has been practiced since the existence of humans for feeding human infants (Ibe et al., 2016).

Breastmilk is the best food for the infant because of its numerous advantages which includes; containing all the nutrients in the correct proportions, having the correct temperature, being easily digested and assimilated, readily produced and available (Frazer \& Cooper, 2003). Breastmilk remains superior to infant formula from the perspective of the overall health of both mother and child (People, 2010). Consequently, it has been recommended that all nursing mothers should breastfeed their infants exclusively in the first six months and successively with complementary feeding for 2years for optimal growth and development (UNICEF, 2013).

One inevitable aspect of improving the health and nutritional status of children is the practice of optimal infant and young child feeding. Important recommendations from international guidelines state that, for normal physical and mental childhood growth as well as for good health in later life, it is important to adequately breastfeed during early childhood.

The elements of infant and young child feeding includes: Early initiation of breast feeding (within 30 minutes of delivery), exclusive breastfeeding, timely introduction of adequate complementary feeding and sustained breastfeeding till 2 years and beyond. According to WHO (2007), planning guide for national implementation of the Global Strategy for Infant and young Child Feeding, exclusive breastfeeding is defined as the act of giving infants only breast milk, excluding solids or any other fluids (including infant formula) except medicines, vitamins, and minerals.

Considering the usefulness contribution of breastfeeding for optimal development, the World Health Organization (WHO) recommends exclusive breastfeeding for six months, followed by addition of complementary feeds thereafter, with continuation of breastfeeding up to or beyond two years (WHO, 2003). Suboptimal breastfeeding is responsible for the death of 1.4 million children and the disability of 44 million globally (Black, Allen, Bhutta, Caulifield, De onis, Ezzati and Rivera, 2008). However, many children are not fed in the recommended way. Many mothers who initiate breast-feeding satisfactorily often start complimentary feeds or stop breast feeding within a few weeks of delivery. Low level of exclusive breastfeeding practice had earlier been documented and some factors associated with that (Ibe et al., 2017). In addition, many children even those who have grown well for the first six months of life, do not receive adequate 
complimentary feeds later on. This may result in malnutrition leading to stunting, wasting and deficiency in most vitamins and micronutrients. Complementary feeding is the change over from exclusive breastfeeding to family foods and characteristically covers the period from 6 - 24 months of age, even though breastfeeding may last to two years of age and beyond. This is a crucial period of growth and development during which nutrient deficiencies and infections contribute globally to higher rates of malnourishment among children below five years of age.

In Abia State, the level of coverage of exclusive breast feeding has stagnated to 30 percent despite all the trainings and retraining of breast feeding focal persons, officers in charge (OICs), breast feeding counsellors and support groups who visit the pregnant and lactating mothers in their homes to counsel them on the need to exclusively breast feed their young infants. Umuahia South L.G.A had benefited from several trainings on infant and young child feeding which yielded poor result as there are still malnourished babies during Postnatal clinics. This problem observed aroused great concern, hence the interest of the researcher to determine the knowledge attitude and practice of mothers with child 0-24 months towards infant and young child feeding in Umuahia South LGA with the view of contributing to filling the gap. The dependent variables studied were the socio demographic characteristics (age, educational qualification, marital status, religion and occupation) while the dependent variables were knowledge, attitude and practice of the nursing mothers.

\section{MATERIALS AND METHODS}

Descriptive survey research design was used for the study which determined the knowledge, attitude and practice of infant and young child feeding in Umuahia South Local Government Area of Abia State. The study was facility based as nursing mothers attending post-natal clinics in the primary health care centers in Umuahia South LGA. That offer routine immunization services were the participants. Multi-stage random sampling method was used to select nine (9) health facilities from the existing thirty-eight (38) public health facilities in the three (3) zones in Umuahia-South LGA. The sample size was made up of 372 respondents selected from the target population of 5325 . Umuahia-South LGA is one of the seventeen LGAs in Abia State Nigeria, located in the Abia central zone with a total population of 181, 816 (85414 males and 96402 females) (National Population Commission, 2006). A structured questionnaire was used as instrument for data collection after establishing the validity and reliability. The questionnaire was divided into four (4) sections. Section A and B elicited the socio-demographic characteristics of the mother and child respectively, section $\mathrm{C}$ revealed the knowledge of mothers on infant and young child feeding while section D elicited the attitude of mothers towards infant and young child feeding while section $E$ addressed the practice of infant and young child feeding. Written consent was obtained from the local Government Chairman, the Health Authority Secretary, officers in charge of the various health facilities and the respondents. Data analysis was done using Statistical Package for Social Science (SPSS).

\section{RESULTS}

\section{Socio-Demographic Characteristics of Mothers with Child 0- 24 Months}

Results of the socio-demographic characteristics of mothers with Child 0-24 months on Table 1 revealed that majority $302(81.2 \%)$ were between the age group of 31-40 years, followed by $50(13.5 \%)$ for age group of 21-30 years, $12(3.2 \%)$ for age group of below 20 years and the least was $8(2.2 \%)$ for age group of 41-50 years. In relation to marital status, 241(64.8\%) were married; single mothers were $125(33.6 \%)$ while separated mothers had only $6(1.6 \%)$. As regards to highest education attainment, majority $164(44.1 \%)$ attended tertiary education, followed by secondary with $105(28.2 \%)$ and primary education recorded $103(27.7 \%)$. Concerning the occupation of the respondents; more $203(54.5 \%)$ were civil/public servant, 140(37.9\%) trading, $12(3.2 \%)$ were for unemployed/house wife, $8(2.2 \%)$ for farming, $6(1.6 \%)$ for artisan and others with $3(0.8 \%)$. Out of 372 respondents interviewed, majority $138(36.8 \%)$ had $3-4$ children, $128(34.4 \%)$ had 1-2 children and $106(28.8 \%)$ had $4-5$ children.

\section{Level of Knowledge of Mothers with Child 0-24 months on Infant and Young Child Feeding}

Table 2 showed the level of the knowledge of mothers with child 0-24 months on infant and young child feeding; majority $332(89.2 \%)$ said yes they have heard about exclusive breastfeeding while $40(10.8 \%)$ answered no, this means that help health education and awareness creation should be capture the remaining $10.8 \%$. Meaning of exclusive breastfeeding; $330(88.7 \%)$ said that exclusive breastfeeding is feeding the baby with the mothers' breast milk only without water or other food or fluid within the first 6 months 20(5.4\%) said it is feeding the baby with water or with infant formula $88.7 \%$ were the group that got the correct meaning of exclusive breastfeeding which indicates that the remaining percentage are not yet aware of the meaning of exclusive breastfeeding. This implies that the awareness creation through the breastfeeding focal persons, officers in-charge of the health facilities, breastfeeding counsellors and support groups yielded good result. Out of 372 of the mothers/care givers, majority 321 said that the child should be exclusively breastfed for 6 months 41(11\%) sais nine months which implies that a good number of mothers know the actual meaning of exclusive breastfeeding which is feeding the baby with the mothers breastmilk only without any other fluid or drink for the first 6 months of life (Ibe et al., 2017). From the interviewed mothers, $310(83.3 \%)$ said it is very good for a baby to be breast fed exclusively for 6 months, 35(9.4\%) said not good, 17(4.6\%) said it is okay and only $10(2.7 \%)$ said they don't know, $9.4 \%, 4.6 \%$ and $2.7 \%$ on the interviewed mothers do not know the benefits of exclusive breastfeeding which means that health workers should further health educate the mothers during every visit to the clinic. From their knowledge, 167(44.9\%) said the consistency of food for babies at 6-9 months should semi-solid, 153(41.1\%) said watery and 52(14\%) said solid. At 9-12 months; 182(48.9\%) said the consistency of food for babies at 9-12 months should solid, $170(45.7 \%)$ said semi-solid and $20(5.4 \%)$ said watery, it is only $44.9 \%$ that knows the consistency of the infant food which is semi solid. 
Attitude of Mothers with Child 0-24 Months of different SocioCharacteristics towards infant and young child feeding

The result in table 3 showed the attitude of mothers with child 0-24 months of different socio-characteristics towards infant and young child feeding; majority $239(64.2 \%)$ strongly agreed that baby should be breastfed exclusively for the first 6 months, 91(24.5\%) agreed, 30(8.1\%) disagreed and 12(3.2\%) strongly disagreed. For colostrum (the first milk) should not be thrown away; 199(53.5\%) strongly agreed, 102(27.4\%) agreed, $71(18.9 \%)$ disagreed and nobody was strongly disagreed. There are no difficulties in breastfeeding babies exclusively; majority $310(83.3 \%)$ strongly agreed, 42(11.3\%) agreed, 10(2.7\%) disagreed and strongly disagreed. Babies should be breastfed day and night; 298(80.1\%) strongly agreed, 62(16.7\%) agreed, $9(2.4 \%)$ disagreed and $3(0.8 \%)$ strongly disagreed. Mothers should feel free to breastfed their babies in the public places; 275(73.9\%) strongly agreed, 55(14.8\%) agreed, 39(10.5\%) disagreed and $3(0.8 \%)$ strongly disagreed. Babies should be introduced to family food at 6 months; 289(77.7\%) strongly agreed, 61(16.4\%) agreed, 17(4.6\%) disagreed and 5(1.3\%) strongly disagreed. The consistency of baby's food should be semisolid; 250(67.2\%) strongly agreed, 99(26.6\%) agreed, 19(5.1\%) disagreed and 4(1.1\%) strongly disagreed. Baby's health is important if the label's preparation instruction is followed; $161(43.3 \%)$ strongly agreed, 199(53.5\%) agreed, 6(1.6\%) disagreed and $6(1.6 \%)$ strongly disagreed. After feeding a baby with infant formula, the remnant should be thrown away; 192(51.6\%) strongly agreed, 100(26.9\%) agreed, 40(10.8\%) disagreed and strongly disagreed.

Relationship between attitude of Mothers with Child 0-24 Months of different Socio-Characteristics (age, marital status, education and occupation) towards infant and young child feeding. The analyzed result showed that there is a statistical significant on level of knowledge of mothers in infant and young child feeding and occupation of the mother $(\mathrm{F}=54.750$ at $\mathrm{p}=0.000 ; 20.531$ at $\mathrm{p}$ $=0.000 ; 20.531$ at $\mathrm{p}=0.00 ; 15.847$ at $\mathrm{p}=0.000)$.

\section{Practice of Infant and Young Child Feeding among Mothers of different socio-Demographic characteristics with Child 0-24 months}

Table 3 showed the practice of infant and young child feeding among mothers of different socio-demographic with child 0-24 months; $220(59.1 \%)$ said yes babies usually put skin to skin with their mothers after delivery, $122(32.8 \%)$ said yes they do give their baby water after delivery while $250(67.2 \%)$ do not. From the mothers, 231(62.1\%) said breast was the first food you gave to the baby. Also, 272(73.1\%) said that sleep with a baby (rooming in) while $100(26.6 \%)$ said no. The mothers were asked on frequency of their baby's feeding from 6 months; majority 180(48.4\%) said four times or more, $63(16.9 \%)$ said 2 times or 3 times, $40(10.8 \%)$ said 8 or more times and $6(1.6 \%)$ said others. The key moments when you need to wash your hands to prevent germs from reaching food; majority 180(48.4\%) said before feeding a child/eating, $80(21.5 \%)$ said after going to the toilet/latrine, $40(10.8 \%)$ said after cleaning a baby's bottom/changing a baby's nappy and $35(9.4 \%)$ said after handling raw food and after handling garbage. The figure 1 showed how long after delivery was a baby put to breast; $33.9 \%$ said within 30 minutes, $33.5 \%$ said within the first hour, $22.6 \%$ said within the first day, $5.4 \%$ said after 24 hours and $2.7 \%$ said after 72 hours. The figure 2 showed the nature of baby feeding; $45.7 \%$ said feeding is done when the baby cries, $32.3 \%$ said feeding is on demand, $8.6 \%$ said after every 3-4 hour, 5.4\% said feeding using a schedule and others. The figure 3 showed the starting of complementary feeding; $51.1 \%$ said 6 months, $22.8 \%$ said at 3 months, $16.1 \%$ said 5 months, $7.3 \%$ said 4 months and $2.7 \%$ said 7 months.

\section{DISCUSSION}

Majority of the respondents were aged 31-40 years. This age group should have grown up when the campaign on infant and young child feeding had taken off in Nigeria, particularly exclusive breastfeeding. It is therefore not surprising more respondents had high level of knowledge, though more outstanding performance was expected considering the reason that they all had formal education and the length of time and efforts committed to this initiative in the area. Correct knowledge responses were expected to be very close to 100 percent instead of 70 percent.

Majority of the respondents had positive attitude towards infant and young child feeding. Knowledge is known to influence attitude and the positive attitude reported in this study might likely be linked to the high level knowledge recorded. However, practice is yet to reach desired level. This situation poses a great concern because there are series of interventions to promote infant and young child feeding going on the study area.

\section{CONCLUSION AND RECOMMENDATIONS}

The practice of infant and young child feeding is yet to reach the desired level despite tremendous effort to promote the initiative in the study area. This study concluded that previous effored are yet to achieve the desired effects in this LGA. There is need for participatory evaluation of ongoing programmes and restrategizing implementation for effectiveness. 
Table 1: Distribution of the Socio-Demographic Characteristics of Mothers with Child 0-24 Months

\begin{tabular}{|c|c|c|}
\hline Variable & Frequency & Percentage (\%) \\
\hline \multicolumn{3}{|l|}{ Age in years } \\
\hline Below 20 years & 12 & 3.2 \\
\hline $21-30$ years & 50 & 13.5 \\
\hline $31-40$ years & 302 & 81.2 \\
\hline $41-50$ years & 8 & 2.2 \\
\hline Above 50 years & 0 & 0.0 \\
\hline Total & 372 & 100.0 \\
\hline \multicolumn{3}{|l|}{ Marital status } \\
\hline Single & 125 & 33.6 \\
\hline Married & 241 & 64.8 \\
\hline Separated & 6 & 1.6 \\
\hline Divorced & 0 & 0.0 \\
\hline Others & 0 & 0.0 \\
\hline Total & 372 & 100.0 \\
\hline \multicolumn{3}{|c|}{ Highest educational qualification } \\
\hline No formal education & 0 & 0.0 \\
\hline Primary level of education & 103 & 27.7 \\
\hline Secondary level of education & 105 & 28.2 \\
\hline Tertiary level of education & 164 & 44.1 \\
\hline Total & 372 & 100.0 \\
\hline \multicolumn{3}{|l|}{ Occupation of the respondents } \\
\hline Unemployed/house wife & 12 & 3.2 \\
\hline Farming & 8 & 2.2 \\
\hline Civil/public servant & 203 & 54.5 \\
\hline Trading & 140 & 37.6 \\
\hline Artisan & 6 & 1.6 \\
\hline Others & 3 & 0.8 \\
\hline Total & 372 & 100.0 \\
\hline \multicolumn{3}{|l|}{ Parity of the respondents } \\
\hline $1-2$ & 128 & 34.4 \\
\hline $3-4$ & 138 & 36.8 \\
\hline $4-5$ & 106 & 28.8 \\
\hline Above 6 & 0 & 0.0 \\
\hline Total & 372 & 100.0 \\
\hline
\end{tabular}

Table 2: Distribution of Mothers with Child 0-24 Months by their Knowledge of Infant and Young Child Feeding

\begin{tabular}{lll}
\hline Variable & Frequency & \\
\hline Have you heard about exclusive breastfeeding & & \\
Yes & 332 & 89.2 \\
No & 40 & 10.8 \\
Total & 372 & 100.0
\end{tabular}

Meaning of exclusive breastfeeding

Feeding the baby with the mothers breast milk only without water or other food or fluid within the first 6 
Total

372

100.0

At what age, should a baby start eating food with addition of breast milk?

3 months

6 months

9 months

12 months

Others

Total

What is the advantages of exclusive breastfeeding?

Very good

Not good

Okay

Don't know

Total

What should the consistency of food be at 6-9 months?

Watery

Semi-solid

Solid

Total

What should the consistency of food be at 9-12 months?

Watery

Semi-solid

Solid

Total
41

321

10

0

0

372

310

35

17

10

372

153

167

52

372

20

170

182

372
11.0

86.3

2.7

0.0

0.0

100.0

83.3

9.4

4.6

2.7

100.0

41.1

44.9

14.0

100.0

5.4

45.7

48.9

100.0

Table 3: Attitude of Mothers with Child 0-24 Months of different Socio-Characteristics towards infant and young child feeding

\begin{tabular}{|c|c|c|c|c|}
\hline Statement & SA & $\mathbf{A}$ & D & SD \\
\hline $\begin{array}{l}\text { Baby should be breastfed exclusively for the first } \\
6 \text { months }\end{array}$ & $239(64.2 \%)$ & $91(24.5 \%)$ & $30(8.1 \%)$ & $12(3.2 \%)$ \\
\hline $\begin{array}{l}\text { Colostrum (the first milk) should not be thrown } \\
\text { away }\end{array}$ & $199(53.5 \%)$ & $102(27.4 \%)$ & $71(18.9 \%)$ & 0 \\
\hline $\begin{array}{l}\text { There are no difficulties in breastfeeding babies } \\
\text { exclusively }\end{array}$ & $310(83.3 \%)$ & $42(11.3 \%)$ & $10(2.7 \%)$ & $10(2.7 \%)$ \\
\hline Babies should be breastfed day and night & $298(80.1 \%)$ & $62(16.7 \%)$ & $9(2.4 \%)$ & $3(0.8 \%)$ \\
\hline $\begin{array}{l}\text { Mothers should feel free to breastfed their babies } \\
\text { in the public places }\end{array}$ & $275(73.9 \%)$ & $55(14.8 \%)$ & $39(10.5 \%)$ & $3(0.8 \%)$ \\
\hline $\begin{array}{l}\text { Babies should be introduced to family food at } 6 \\
\text { months }\end{array}$ & $289(77.7 \%)$ & $61(16.4 \%)$ & $17(4.6 \%)$ & $5(1.3 \%)$ \\
\hline $\begin{array}{l}\text { The consistency of baby's food should be semi- } \\
\text { solid }\end{array}$ & $250(67.2 \%)$ & $99(26.6 \%)$ & $19(5.1 \%)$ & $4(1.1 \%)$ \\
\hline $\begin{array}{l}\text { Baby's health is important if the label's preparation } \\
\text { instruction is followed }\end{array}$ & $161(43.3 \%)$ & $199(53.5 \%)$ & $6(1.6 \%)$ & $6(1.6 \%)$ \\
\hline $\begin{array}{l}\text { After feeding a baby with infant formula, the } \\
\text { remnant should be thrown away }\end{array}$ & $192(51.6 \%)$ & $100(26.9 \%)$ & $40(10.8 \%)$ & $40(10.8 \%)$ \\
\hline
\end{tabular}

Strongly Agree (SA), Agree (A), Disagree (D), Strongly Disagree (SD) 
Table 4: Practice of Infant and Young Child Feeding among Mothers of different socio-Demographic with Child 0-24 months

\begin{tabular}{|c|c|c|}
\hline Statements & Frequency $(\mathrm{N}=372)$ & Percentage (\%) \\
\hline \multicolumn{3}{|c|}{ Was the baby put skin to skin with you after delivery? } \\
\hline Yes & 220 & 59.1 \\
\hline No & 152 & 40.9 \\
\hline Total & 372 & 100.0 \\
\hline \multicolumn{3}{|c|}{ Did you give your baby water after delivery? } \\
\hline Yes & 122 & 32.8 \\
\hline No & 250 & 67.2 \\
\hline Total & 372 & 100.0 \\
\hline \multicolumn{3}{|l|}{ What was the first food you gave to the baby? } \\
\hline Breast milk & 231 & 62.1 \\
\hline Plain water & 19 & 5.1 \\
\hline Glucose water & 108 & 29.0 \\
\hline Infant formular & 9 & 2.4 \\
\hline Family food & 5 & 1.3 \\
\hline Total & 372 & 100.0 \\
\hline \multicolumn{3}{|l|}{ Do you sleep with your baby (rooming in)? } \\
\hline Yes & 272 & 73.1 \\
\hline No & 100 & 26.6 \\
\hline Total & 372 & 100.0 \\
\hline \multicolumn{3}{|c|}{ How often is your baby fed from 6 months? } \\
\hline At 0 time & 10 & 2.7 \\
\hline 1 time & 10 & 2.7 \\
\hline 2 times & 63 & 16.9 \\
\hline 3 times & 63 & 16.9 \\
\hline 4 or more & 180 & 48.4 \\
\hline 8 or more times & 40 & 10.8 \\
\hline Others & 6 & 1.6 \\
\hline Total & 372 & 100.0 \\
\hline \multicolumn{3}{|c|}{ What are the key moments when you need to wash your hands to prevent germs from reaching food? } \\
\hline After going to the toilet/latrine & 80 & 21.5 \\
\hline $\begin{array}{l}\text { After cleaning a baby's bottom/changing a } \\
\text { baby's nappy }\end{array}$ & 40 & 10.8 \\
\hline Before feeding a child/eating & 180 & 48.4 \\
\hline After handling raw food & 35 & 9.4 \\
\hline After handling garbage & 35 & 9.4 \\
\hline Others & 2 & 0.5 \\
\hline Total & 372 & 100.0 \\
\hline
\end{tabular}




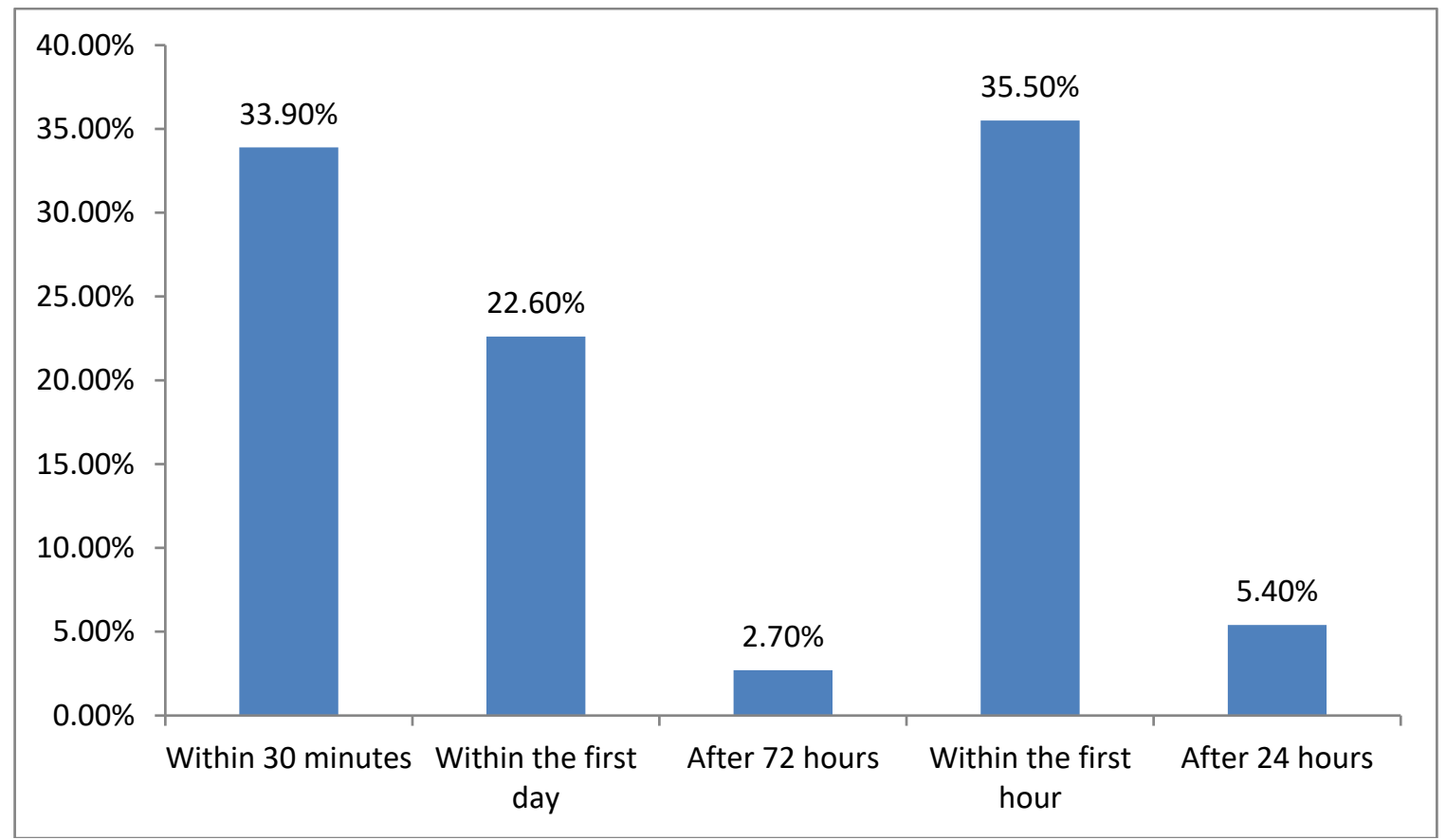

Figure 1: How long after birth should a baby be put to breast?

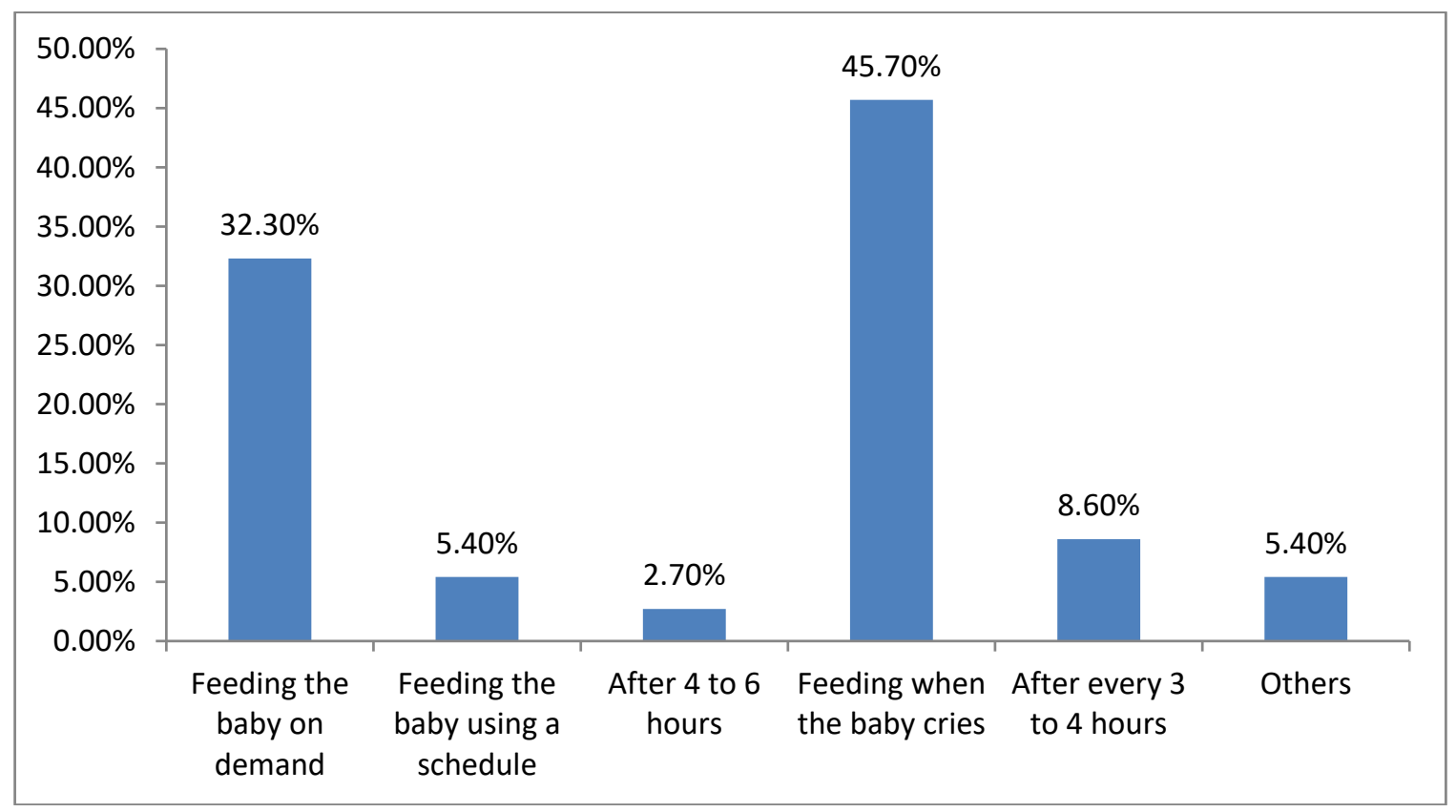

Figure 2: When do you feed your baby? 


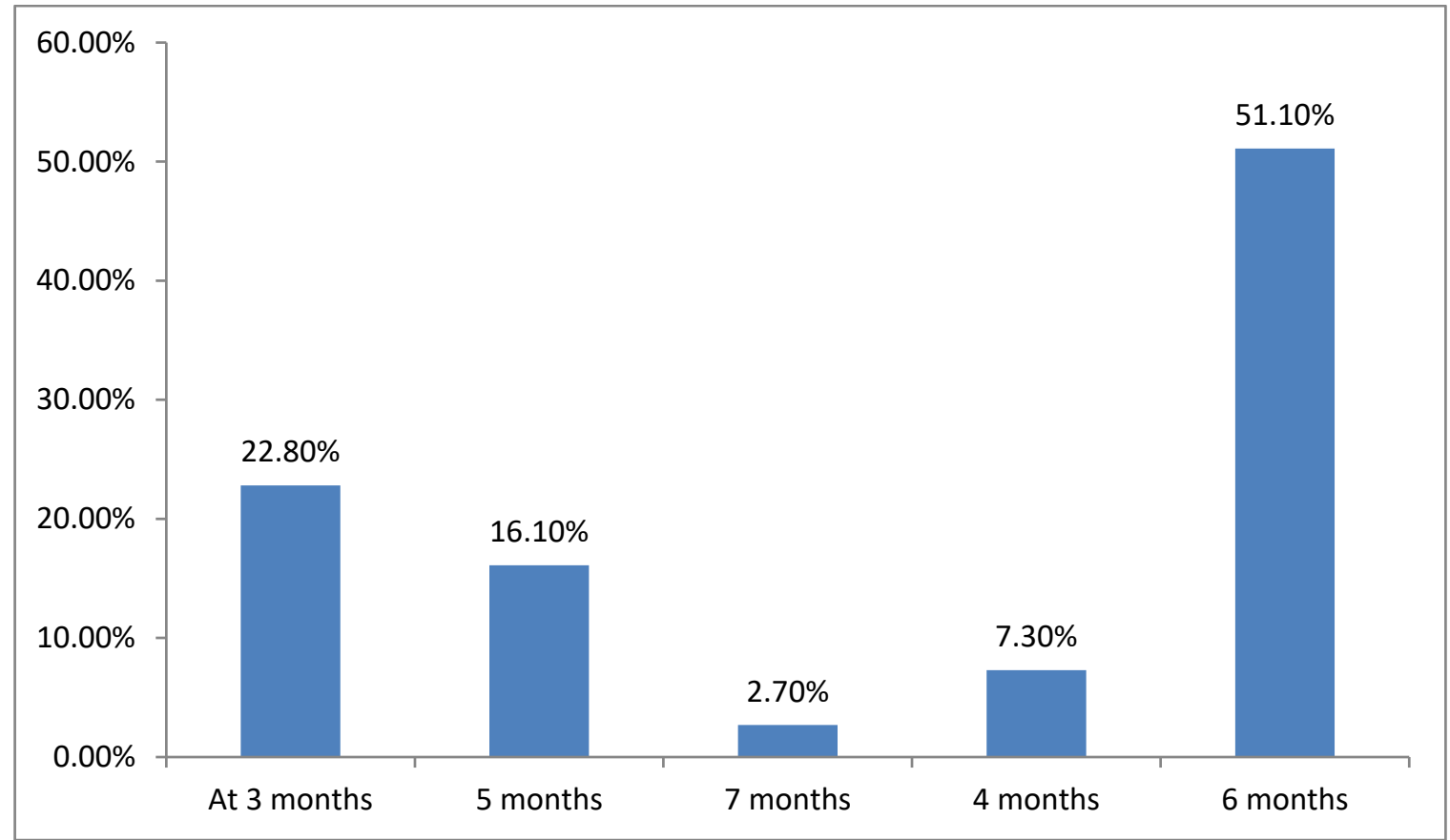

Figure 3: When did you start complementary feeding?

\section{REFERENCES}

[1] Black, R. E., Morris, S. S.\& Bryce, (2008). Where and why are 10 million children dying every year? Lancet. 361:2226-2234.

[2] Frazer, D.M. \& Cooper, M.A. (eds.) (2003). Myles textbook for midwives. Edition. London: Churchill Livingstone.

[3] Ibe, S. N. O., Obasi., Nwoke, E. A., Nwufo, C.R., Ebirim, C.I.C., Osuala, E.O., Amadi, C.O., Ezenwuba, C.O. (2019). Cultural practices on infant feeding and nursing-mothers' adoption of exclusive breastfeeding practice in Imo State Nigeria. MOJ Public Health, 5(5); 1-8, DOI: 10.15406/mojph.2017.05.00141

[4] National Population Commission (2006) Federal Republic of Nigeria. Official Gazette Legal Notice of Publication of 2006. Census Final Result (2nd February, 2009). Page 6 Vol 69. Abuja.

[5] People, H. (2010). Healthy Milk, Healthy Baby Chemical Pollution and Mother's Milk. Centers for Disease Control and Prevention, Atlanta, Georgia, Natural Resources Defense Council.

[6] World Health Organization. (2010). Guidelines on HIV and Infant feeding. Available at www.who.int/documents. Accessed on 2 February 2017.

[7] World Health Organization. (2007). Exclusive breastfeeding. Available at www.whoint/child-adolessent-he. Accessed on 2 February 20017.

[8] World Health Organization (2003). 10 facts on breastfeeding. Available http://www.who.int/features/factfiles/breastfeeding/facts/en/.

[9] World Health Organization. (2002). World Health Report: Reducing risks and promoting healthy life. Available at www.who.int/whr/2002. Accessed on 2 February 20017.

[10] World Health Organization. (2001). Infant and Young child nutrition. 54 World Health Assembly May 14-22. Geneva.

[11] World Health Organization. (2000). Global strategy for Infant and Young child feeding.

Available at www.who.int/nutrition/publication. Accessed on 2 February 20017.

[12] World Health Organization. (1992). Traditional Birth Attendants. World Health Organization Report Geneva.

\section{AUTHORS}

First Author - M. O Kalu, Department of Public Health, School of Health Technology, Federal University of Technology, Owerri, Imo State, Nigeria., marykalu1968@gmail.com Second Author - S.N.O. Ibe, Department of Public Health, School of Health Technology, Federal University of Technology, Owerri, Imo State, Nigeria. 